\title{
Land surface temperature retrieval and validation from Landsat 8 using the Improved Single Channel (ISC) algorithm
}

Savannah Tâmara Lemos da Costa* ${ }^{{ }_{1}}$, Lucas Ribeiro Diaz', Pâmela Suélen Käfer', Eduardo André Kaiser', Nájila Souza da Rocha', and Silvia Beatriz Alves Rolim', 'Geologic Remote Sensing Laboratory (LabSRGeo), State Research Center for Remote Sensing and Meteorology (CEPSRM), Federal University of Rio Grande do Sul (UFRGS), Porto Alegre, Rio Grande Do Sul, Brazil.

Copyright 2021, SBGf - Sociedade Brasileira de Geofísica

This paper was prepared for presentation during the $17^{\text {th }}$ International Congress of the Brazilian Geophysical Society held in Rio de Janeiro, Brazil, 16-19 August 2021.

Contents of this paper were reviewed by the Technical Committee of the $17^{\text {th }}$ International Congress of the Brazilian Geophysical Society and do not necessarily represent any position of the SBGf, its officers or members. Electronic reproduction or storage of any part of this paper for commercial purposes without the written consent of the Brazilian Geophysical Society is prohibited.

\section{Abstract}

The Land Surface Temperature (LST) indicates the spatiotemporal distribution of the energy exchange in the Earth's landscapes. We retrieved and validated the LST by the Improved Single Channel (ISC) algorithm using Landsat 8 data. To perform this approach, we selected a dune field with $99.53 \%$ of quartz $\left(\mathrm{SiO}_{2}\right)$ located between the municipalities of Cidreira and Tramandaí, state of Rio Grande do Sul (RS), Brazil. For LST estimation, prior knowledge of Land Surface Emissivity (LSE) is needed, and it was calculated with the Normalized Difference Vegetation Index (NDVI) threshold. To make it efficient and practical, the ISC algorithm was implemented as an ArcGIS toolbox. The LST ranged from 297 to $316 \mathrm{~K}$, with a mean of $311.7 \mathrm{~K}$ and a standard deviation of $2.1 \mathrm{~K}$ was calculated. In the validation, we reached an error of $0.39 \mathrm{~K}$, which is in agreement with other studies, where the errors reached from 0.27 to $1 \mathrm{~K}$. This result showed that the ISC algorithm has good accuracy and its implementation as a toolbox revealed an accurate and practical way to calculate the LST using Landsat 8 thermal data. This brings advantages for studies of Earth's energy budget and Urban Heat Island (UHI) effects which may require accurate LST mapping from many satellite data.

\section{Introduction}

The Land Surface Temperature (LST) indicates the spatiotemporal distribution of the energy exchange in the Earth's landscapes (Malbeteau, 2017; Morrison, 2020). It is a variable that plays an important role in a variety of research fields, such as climate change, urban planning, agriculture, environmental monitoring, and geology (Jiménez-Muñoz et al., 2014; Rolim et al., 2020; Tardy et al., 2016).

In remote sensing, the LST is largely retrieved using data from the Thermal Infrared (TIR) region (Jiménez-Muñoz, 2014; Käfer et al., 2019; Kuenzer \& Dech, 2013; Sobrino et al., 2004; Tang \& Li, 2014), and satellites such as the EOS-Terra, Sentinel-3 and Landsat 8 can provide thermal data in moderate spatial and spectral resolutions. The Landsat 8, as an example, has the Thermal Infrared Sensor (TIRS) onboard that registers the information in two bands: $10(10.6-11.19 \mu \mathrm{m})$ and $11(11.5-12.51 \mu \mathrm{m})$, with a 100-m resolution resampled to $30 \mathrm{~m}$ (Ihlen, 2019; Malakar, 2018).

Estimating LST through data measured from space is still a challenge. It is necessary to know the Land Surface Emissivity (LSE) and correct the atmospheric effects on the at-sensor radiance. In addition, both variables LST and LSE have a non-linear correlation, constituting an indeterminate system with infinite solutions.

To solve this issue, LST retrieval algorithms have been developed based on Radiative Transfer Equation (RTE). One of the first single channel algorithms consists of the RTE inversion (Sobrino et al., 2004). It requires an atmospheric vertical profile and radiative transfer model to calculate the transmittance, downwelling and upwelling radiance of the atmosphere. In order to reduce the dependence on excessive atmospheric variables, other algorithms were created such as Monowindow (MW) (Qin; Karnieli \& Berliner, 2001), Generalized Single Channel (GSC) (Jiménez-Muñoz et al., 2014), and Improved Single Channel (ISC) (Cristóbal et al., 2018).

The accuracy of these algorithms is influenced by sensor type, atmospheric conditions, water vapor content, and surface composition. Study by Qin; Karnieli \& Berliner (2001) showed an error in LST of less than $0.4 \mathrm{~K}$ for the MW algorithm on Landsat 6 data. Sobrino et al. (2004) obtained an error of 0.9-2.2 $\mathrm{K}$ with the same algorithm on Landsat 5 data. Wang et al (2015) obtained an accuracy of $1.4 \mathrm{~K}$ in LST from Landsat 8 data, while Sobrino et al. (2008) found an error of $2.25 \mathrm{~K}$.

The GSC algorithm developed by Jiménez-Muñoz \& Sobrino (2003) made the LST estimation dependent only on the LSE and water vapor. Many authors reported LST errors between 2.94 and $4 \mathrm{~K}$ in Landsat 8 data experiments (Li \& Jiang, 2018; Sobrino et al. 2008; Jiménez-Muñoz et al., 2010; Yu et al., 2014). In order to increase the SCG accuracy, Cristóbal et al. (2018) developed the ISC algorithm, where the mean atmospheric temperature was added in the LST retrieval. The ISC presented errors of 1 $\mathrm{K}$ for Landsat 8 data. However, a study by Li et al. (2019) showed smaller errors of $0.3-0.7 \mathrm{~K}$ in a polar region, whereas Käfer et al. (2019) reached an error of $0.27 \mathrm{~K}$ in the dune field of Cidreira using spectral library emissivity.

Studies of Earth's energy budget and UHI effects may require an accurate LST mapping from a bulk of satellite images, either for spatial-temporal analysis or LST estimation of large areas (Tang \& Li, 2014). Therefore, this paper aimed to validate the LST retrieved by the ISC algorithm using Landsat 8 data. To perform the LST retrieval efficiently and practical, the ISC algorithm was implemented as an ArcGIS toolbox. 


\section{Methods}

This paper focuses on the validation of the LST retrieved by the ISC using Landsat 8 data. We chose this algorithm because it has shown high accuracy in field validations (Käfer, 2019; Li et al., 2019). For LST estimation, prior knowledge of LSE and atmospheric variables is needed. Thus, the equations for calculating the LSE, atmospheric variables and LST estimation are presented below.

\section{Land Surface Emissivity (LSE) estimation}

The LSE is an intrinsic property of each natural material and indicates the fraction of radiation it emits. It is necessary to know the LSE to retrieve the LST, as both variables are closely associated (Kuznetsov et al. 2012; Olsen, 2007).

Several methods of LSE estimation are known (Tang \& $\mathrm{Li}$, 2014; Sekertekin \& Bonafoni, 2020). We chose the Normalized Difference Vegetation Index threshold (NDVI ${ }^{\mathrm{THM}}$ ) because NDVI has a statistical relationship with emissivity and can be easily derived from the reflectance of red and Near Infrared (NIR) bands, respectively bands 4 and 5 of Landsat 8 (Käfer et al., 2019), according Eq. (1).

$$
N D V I=\frac{\rho_{N I R}-\rho_{\text {red }}}{\rho_{N I R}+\rho_{\text {red }}}
$$

wherein $\rho_{N I R}$ is the reflectance of the NIR band and $\rho_{\text {red }}$ is the reflectance of the red band.

The NDVITHM method makes correlations between the NDVI of soil $\left(N D V I_{s}\right)$ and vegetation $\left(N D V I_{v}\right)$ to estimate the emissivity through the following approaches: If $N D V I<N D V I_{S}$, the pixel assumes the soil emissivity $\left(\varepsilon_{s}\right)$. If $N D V I>N D V I_{v}$, then the pixel is fully vegetated and assumes the vegetation emissivity $\left(\varepsilon_{v}\right)$. If $N D V I_{S} \leq N D V I \leq N D V I_{v}$ is a mixed pixel (soil and vegetation), the Eq. (2), (3) and (4) must be applied to calculate the emissivity.

$$
\begin{gathered}
\varepsilon=\varepsilon_{v} \mathrm{P}_{V}+\varepsilon_{s}\left(1-\mathrm{P}_{V}\right)+d \varepsilon \\
\mathrm{P}_{V}=\left(\frac{N D V I-N D V I_{s}}{N D V I_{v}-N D V I_{s}}\right)^{2} \\
d \varepsilon=\left(1-\varepsilon_{s}\right)\left(1-\mathrm{P}_{V}\right) \mathrm{F} \varepsilon_{v}
\end{gathered}
$$

Wherein $\varepsilon$ is the mixed pixel emissivity; $\varepsilon_{S}=0.94 \varepsilon_{v}=0.99$ (Sobrino \& Raissourri, 2000); $\mathrm{P}_{V}$ is the proportion of vegetation cover; $N D V I_{s}=0.157$ e $N D V I_{v}=0.727$ (Van Griend \& Owe (2000); $d \varepsilon$ refers to the cavity effect on rough surfaces ( $d \varepsilon=0$ for flat surfaces); $F$ is the geometric factor equal to 0.55 (Sekertekin \& Bonafoni, 2020).

\section{Atmospheric Variables}

The atmospheric variables for ISC comprise the water vapor content $(\omega)$ and the mean atmospheric temperature $\left(T_{a}\right)$. They can be obtained using the relative humidity $(\phi r)$ and the temperature of the first layer $\left(T_{0}\right)$, from a weather station or vertical profile of the atmosphere, either interpolated or from radiosonde.

A consistent atmospheric vertical profile is provided by the Atmospheric Correction Parameter Calculator (ATMCORR) (Barsi et al., 2003; 2005). This tool generates an interpolated profile with reanalysis data from the National Center for Environmental Prediction (NCEP) (Saha, 2014). In this study, data from an ATMCORR interpolated profile was used in the LST retrieval, presented in the results.

Eq. (5) and (6) were used to calculate the atmospheric water vapor content (Leckner, 1978).

$$
\omega=\frac{0.493 \varphi_{r} P_{s}}{T_{o}}
$$

wherein $\omega$ is the water vapor in $\mathrm{g} . \mathrm{cm}^{-2}$ and $\phi r$ is the relative humidity in the first layer of the vertical profile.

$$
P_{s}=\exp \left(26.23-\frac{5416}{T_{o}}\right)
$$

wherein $P_{s}$ is the partial pressure and $T_{0}$ is the temperature in the first layer of the vertical profile.

According to Qin; Karnieli \& Berliner (2001), calculating the mean atmospheric temperature $\left(T_{a}\right)$ only uses the temperature in the first layer of the vertical profile. Thus, we implement the Eq. (7) for the $T_{a}$ calculation.

$$
T_{a}=16.011+0.9262 T_{o}
$$

wherein $T_{o}$ is the temperature in the first layer of the vertical profile.

\section{Land Surface Temperature (LST) retrieval}

For LST retrieval, band 10 from Landsat 8 was used in the ISC algorithm. We chose this band since it has less atmospheric influence if compared to band 11 (JiménezMuñoz et al., 2014).

First, the radiometric calibration was applied in the band 10 , where digital numbers were converted to at-sensor radiance (Ihlen, 2019). Subsequently, the brightness temperature at the Top of the Atmosphere (TOA) was derived from at-sensor radiance (Ihlen, 2019). Then, brightness temperature, at-sensor radiance, LSE and atmospheric variables were used in the ISC algorithm.

\section{Improved Single Channel algorithm}

ISC algorithm was developed by Cristóbal et al. (2018) and relies on the LSE, water vapor content, mean atmospheric temperature, at-sensor radiance, and brightness temperature at TOA for LST retrieval.

The LST is estimated according to Eq. (8), (9), and (10).

$$
T_{s}=\gamma\left[\frac{1}{\varepsilon}\left(\psi_{1} L_{\text {sens }}+\psi_{2}\right)+\psi_{3}\right]+\delta
$$


wherein $T_{s}$ is the LST, $\varepsilon$ is the LSE, $L_{\text {sens }}$ is the at-sensor radiance, and $\psi_{1}, \psi_{2}, \psi_{3}$ are atmospheric functions. The $V$ and $\delta$ are derived from the Planck equation, as follows:

$$
\begin{gathered}
\gamma=\left\{\frac{C_{2} L_{\text {sen }}}{\left(B T_{\text {TOA }}\right)^{2}}\left[\frac{\lambda^{4} L_{\text {sen }}}{C_{1}}+\frac{1}{\lambda}\right]\right\}^{-1} \\
\delta=-\gamma L_{\text {sen }}+\text { BTTOA }
\end{gathered}
$$

wherein $C_{1}$ is equal to $1.19104 \times 10^{8} \mathrm{Wum}^{-2} \mathrm{sr}^{-1}$ and $\mathrm{C}_{2}$ is equal to $14387.7 \mu \mathrm{m}$, and $\lambda$ is the effective wavelength in $\mu \mathrm{m}$.

We applied Eq. (11), (12), and (13) for atmospheric functions.

$$
\begin{gathered}
\psi_{1}=-7.2122 \omega^{2}+0.00005 T_{a}^{2}-2.452321 \omega \\
-0.026275 T_{a}-0.00005 T_{a}^{2} \omega+0.02317 T_{a} \omega \\
+0.04663 T_{a} \omega^{2}-0.00007 T_{a}^{2} \omega^{2}+4.47297 \\
\psi_{2}=89.61569 \omega^{2}-0.00038 T_{a}^{2}+106.55093 \omega \\
+0.21578 T_{a}+0.00141 T_{a}^{2} \omega-0.78444 T_{a} \omega \\
-0.5732 T_{a} \omega^{2}+0.00091 T_{a}^{2} \omega^{2}-30.37028 \\
\psi_{3}=-14.65955 \omega^{2}-0.0001 T_{a}^{2}-79.95838 \omega \\
+0.4181 T_{a}-0.00091 T_{a}^{2} \omega+0.54535 T_{a} \omega \\
+0.09114 T_{a} \omega^{2}-0.00014 T_{a}^{2} \omega^{2}-3.76184
\end{gathered}
$$

Figure 1 shows the steps of the methods used for the LST retrieval. The above equations were implemented as a toolbox with the model builder from ArcGIS software (ESRI, 2021). This task automatized the algorithm steps making practical the LST extraction.

Is important to note that the NDVI ${ }^{\text {тнм }}$ method was previously implemented as a toolbox by Sekertekin \& Bonafoni (2020) and Walawender et al. (2012). We used the scheme developed by Sekertekin \& Bonafoni (2020) modifying only the NDVI values of soil and vegetation according to Van Griend \& Owe (2000).

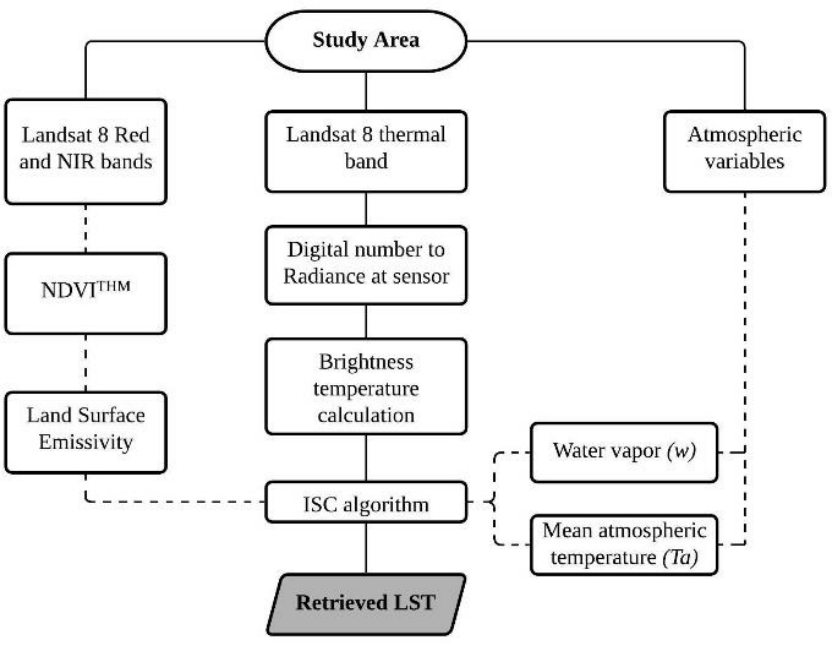

Figure 1 - Steps for LST retrieval using the ISC algorithm.

\section{Data for LST retrieval and validation}

For LST estimation by ISC algorithm and validation, we chose a field of transgressive dunes on the north coast of Rio Grande do Sul (RS) state, Brazil, between the municipalities of Cidreira and Tramandaí (Figure 2).



Figure 2 - Chosen area for LST retrieval.

This area has about $30 \mathrm{~km}^{2}$ and is known as Cidreira field dunes. It is an experimental field considered pseudoinvariant and homogeneous in terms of emissivity and composition. The fine sands (sizes between 125-250 $\mu \mathrm{m}$ ) are composed of $99.53 \%$ quartz (SiO2) and $0.47 \%$ heavy minerals (Käfer et al., 2019; Pittigliani and Rolim, 2017).

A field campaign at Cidreira dunes was carried out on March 14, 2018 by the UFRGS Geologic Remote Sensing Laboratory. In the field, the radiance of quartz was measured, from which the emissivity (0.9798) and radiometric temperature $(314.19 \mathrm{~K})$ were derived, see Käfer et al. (2019) for more detail.

Regarding remote sensing data, we acquired a Landsat 8 OLI/TIRS Level-1 scene (USGS, 2020) registered on March 14, 2018, at 1:12 PM, path 220 and row 81, when the solar angles were $47.37^{\circ}$ (zenith) and $55.75^{\circ}$ (azimuth). 
For atmospheric variables, an interpolated profile was generated by ATMCORR from which we obtained the relative humidity of $70.53 \%$ and the temperature in the first layer of $298.06 \mathrm{~K}$.

These atmospheric data with the 4, 5, and 10 bands from Landsat 8, and emissivity were applied in the LST calculation. The quartz emissivity of 0.9798 was assigned as soil emissivity and the radiometric temperature of $314.19 \mathrm{~K}$ was used in the validation. The Temperaturebased method was used in this study to validate the LST estimated by ISC. According to Sekertekin \& Bonafoni (2020), this method consists in the comparison between LST retrieved from remote sensing data with ground measurements at the satellite overpass.

Remote sensing data, quartz emissivity and atmospheric variables from Cidreira dunes were placed as parameters in the toolbox for the automatic extraction of LST. Figure 3 show the tool interface, where the parameters must be input to retrieve the LST. Red (B4) and NIR (B5) bands, soil emissivity (Es) and vegetation emissivity (Ev) are required for LSE estimation. Thermal band (B10), Relative Humidity $(R H)$ in percentage and the temperature of the first layer $\left(T_{0}\right)$ in Kelvin are necessary to LST calculation.

The scene metadata also is needed to provide the coefficients used in the radiometric calibration, reflectance and brightness temperature calculations. In addition, the user must input an area boundary shapefile for which the LST is to be calculated. In our study case, a shapefile from Cidreira field dunes was used.
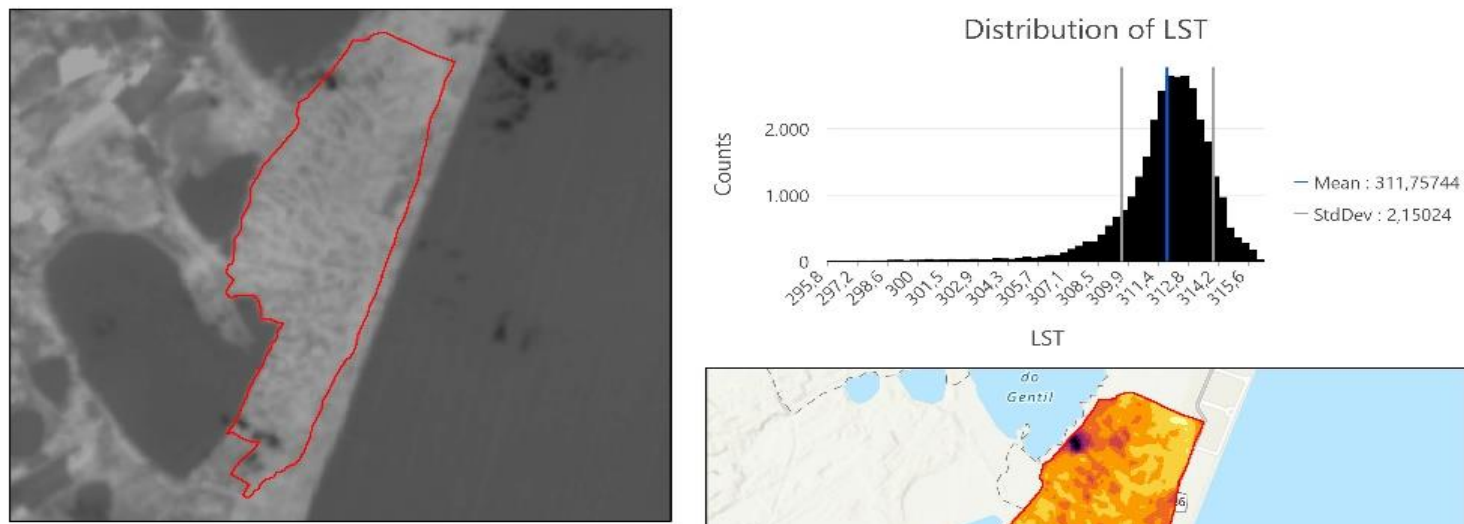

LST

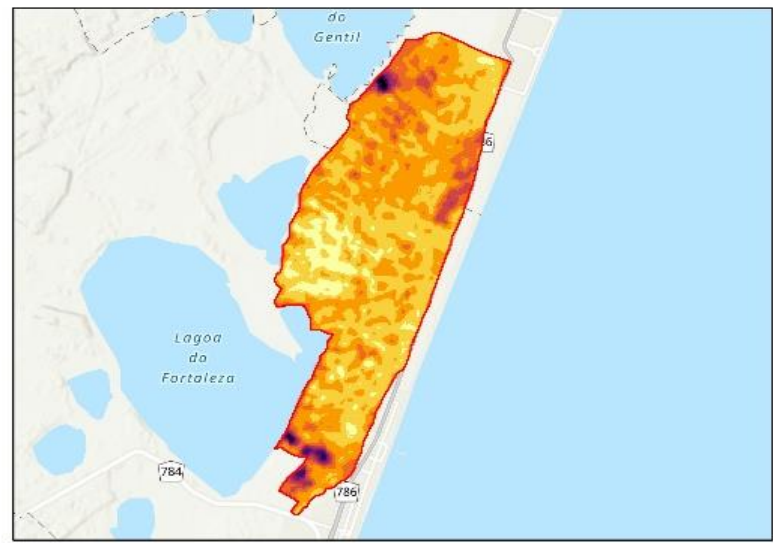

Figure 4 - LST retrieved over the Cidreira field dunes.

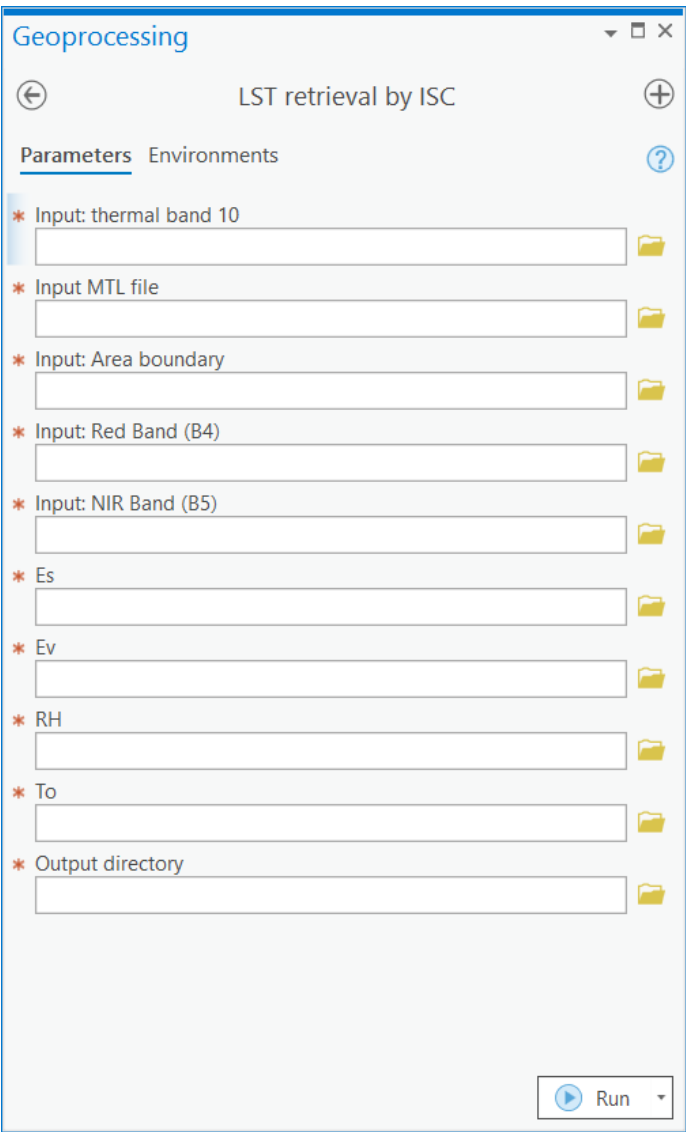

Figure 3- Tool interface where the parameters were placed.

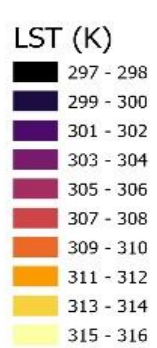




\section{Results and Discussions}

The LST over Cidreira field dunes was obtained after running the tool. Minimum LST of 297-300 K was calculated in small areas where we observed cloud cover. Maximum LST of $315-316 \mathrm{~K}$ was observed along the dune field with a concentration in the southwest region. The mean LST was about $311.7 \mathrm{~K}$ with a standard deviation of $2.1 \mathrm{~K}$. Figure 4 shows the LST mapping result and a histogram of temperature distribution.

In the validation, an LST of $313.8 \mathrm{~K}$ approximately was calculated at the same location as the field measurement. When compared with the radiometric temperature of $314.19 \mathrm{~K}$ we obtained an error of $0.39 \mathrm{~K}$. This value is in accordance with errors reached with the use of ISC for LST retrieval. Cristóbal et al. (2018), as an example, obtained an error of $1 \mathrm{~K}$. Li et al. (2019) showed errors of 0.3-0.7 K in a polar region, whereas Käfer et al. (2019) obtained an error of $0.27 \mathrm{~K}$ in a dune field using spectral library emissivity, and of $0.6 \mathrm{~K}$ for quartz emissivity measured in the field. Therefore, we reached a suitable LST error with the application of the ISC algorithm.

Using the ISC algorithm, attention must be given to the location for which the LST is calculated, as the accuracy of the LST is associated with atmospheric conditions and the uncertainties generated in the estimation of the LSE. According to Dash (2002), emissivity with $1 \%$ of error in a high humidity atmosphere can produce an error in the LST of $0.3 \mathrm{~K}$, whereas in an atmosphere with low humidity, this error in LST can reach $0.7 \mathrm{~K}$. In our application at Cidreira field dunes, the target composition for the NDVIтнм method and the atmospheric conditions were satisfactory to obtain a small error in the LST retrieval by ISC algorithm, as shown in the validation and in a study by Käfer et al. (2019).

The toolbox developed and implemented in this study performed the LST estimation practical and useful for potential final users. It allowed the automatic LST extraction through the ISC algorithm of good accuracy.

\section{Conclusions}

This study validated the LST retrieved by the ISC algorithm using Landsat 8 data. We chose the area of Cidreira dunes in the state of Rio Grande do Sul (RS), Brazil, for LST estimation and validation. The LST ranged from 297 to 316 $\mathrm{K}$, with a mean of $311.7 \mathrm{~K}$ and a standard deviation of 2.1 $\mathrm{K}$ was calculated. In the validation, we reached an error of $0.39 \mathrm{~K}$, which is in agreement with other studies.

The accuracy of LST estimation through the ISC algorithm depends on the method used in the LSE estimation, atmospheric conditions, and land cover type. In this study, we chose a dune field pseudo-invariant and composed of $99.53 \%$ quartz, the emissivity measured in-situ was assigned as soil emissivity in the NDVI тнм method, which contributed to a smaller error in the validation. Moreover, the atmospheric variables derived from the ATMCORR showed suitable for LST estimation.

In this study, the ISC algorithm showed good accuracy for LST retrieval using Landsat 8 thermal data. It was implemented as a toolbox for automatic LST retrieval.
Therefore, this study revealed an accurate and practical way to LST calculation using satellite data of moderated resolution, bringing advantages for studies of Earth's energy budget and urban heat islands effects which may require accurate LST mapping from a bulk of satellite images. Finally, we can see this as an advantage for studies of climate change, such as the detection of urban heat islands, where the retrieval of LST in a big data environment can be time consuming.

The ArcGIS Toolbox for automatic LST retrieval using the ISC algorithm is available in the Github repository https://github.com/savannahtldc/LSTretrievalbyISCtoolbox for download. Users that would like to use this tool, please cite this paper and don't hesitate to contact the authors for any questions.

\section{Acknowledgments}

This research was supported by the Geologic Remote Sensing Laboratory of the Centro Estadual de Pesquisas em Sensoriamento Remoto and was financed, in part, by the Coordination for Improvement of Higher Education Personnel - CAPES (Coordenação de Aperfeiçoamento de Pessoal de Nível Superior). The Landsat 8 data were courtesy of the US Geological Survey (USGS).

\section{References}

BARSI, J. A. et al. 2005. Validation of a web-based atmospheric correction tool for single thermal band instruments. In: BUTLER, J. J. (Ed.). Earth Observing Systems $\quad X$ SPIE, 5882, p. $58820 \mathrm{E}$. https://doi.org/10.1117/12.619990

BARSI, J. A. et al. 2003. An Atmospheric Correction Parameter Calculator for a Single Thermal Band EarthSensing Instrument. In: International Geoscience and Remote Sensing Symposium (IGARSS), 5, 3014-3016. https://doi.org/10.1109/IGARSS.2003.1294665

CRISTÓBAL, J. et al. 2018. An Improved Single-Channel Method to Retrieve Land Surface Temperature from the Landsat-8 Thermal Band. Remote Sensing, 10(3), 431. https://doi.org/10.3390/rs10030431

DASH, P. et al. 2002. Land surface temperature and emissivity estimation from passive sensor data: Theory and practicecurrent trends. International Journal of Remote Sensing, 23(13), https://doi.org/10.1080/01431160110115041

ESRI. ArcGIS Tutorial. 2021. Available at: https://desktop.arcgis.com/en/arcmap/10.3/main/getstarted/arcgis-tutorials.htm. Accessed on April 28, 2021.

IHLEN, V. 2019. Landsat 8 (L8) Data Users Handbook. U.S. Geological Survey (USGS), version 5.0. U. S. Geological Survey. Available at: <https://www.usgs.gov/media/files/ Landsat-8-data-users-handbook>.

JIMÉNEZ-MUÑOZ, J. C. et al. 2014. Land surface temperature retrieval methods from Landsat-8 thermal infrared sensor data. IEEE Geoscience and Remote Sensing Letters, 
Institute of Electrical and Electronics Engineers Inc., 11(10), 1840-1843. https://doi.org/10.1109/LGRS.2014.2312032

JIMÉNEZ-MUÑOZ, J. C.; SOBRINO, J. A. 2003. A generalized single-channel method for retrieving land surface temperature from remote sensing data. Journal of Geophysical Research, 108(22). https://doi.org/10.1029/2003JD003480

KÄFER, P. S. et al. 2019. Land surface temperature retrieval by Landsat 8 thermal band: Applications of laboratory and field measurements. IEEE Journal of Selected Topics in Applied Earth Observations and Remote Sensing, 12(7), 2332-2341.

KUENZER, C.; DECH, S. 2013. Thermal remote sensing Sensors, Methods, Applications. Dordrecht: Springer Netherlands, v. 17. 287-313 p. (Remote Sensing and Digital Image Processing, v. 17). ISSN 15673200. ISBN 9789400766389. Available at: <http://link.springer.com/10.1007/978-94-007-6639-6>.

KUZNETSOV, A. et al. 2012. Remote Sensing of the Environment and Radiation Transfer. Berlin, Heidelberg: Springer Berlin Heidelberg. https://doi.org/10.1007/978-3-64214899-6

LECKNER, B. 1978. The spectral distribution of solar radiation at the earth's surface-elements of a model. Solar Energy, 20(2), 143-150. https://doi.org/10.1016/0038-092X(78)901871

LI, S.; JIANG, G. M. 2018. Land surface temperature retrieval from Landsat-8 data with the generalized split-window algorithm. IEEE Access, 6, 18149-18162. https://doi.org/10.1109/ACCESS.2018.2818741

LI, Y. et al. 2019. An Improved Single-Channel Polar Region Ice Surface Temperature Retrieval Algorithm Using Landsat-8 Data. IEEE Trans. Geosci. Remote. Sens. 57(11), 8557-8569. http://dx.doi.org/10.1109/TGRS.2019.2921606

MALAKAR, N. K. et al. 2018. An Operational Land Surface Temperature Product for Landsat Thermal Data: Methodology and Validation. IEEE Transactions on Geoscience and Remote Sensing, 56(10), 5717-5735. https://doi.org/10.1109/TGRS.2018.2824828

MALBÉTEAU, Y. et al. 2017. Normalizing land surface temperature data for elevation and illumination effects in mountainous areas: A case study using ASTER data over a steep-sided valley in Morocco. Remote Sensing of $\begin{array}{lr}\text { Environment, } & 189, \\ \text { 25-39. }\end{array}$ https://doi.org/10.1016/j.rse.2016.11.010

MORRISON, W. et al. 2020. Atmospheric and emissivity corrections for ground-based thermography using 3D radiative transfer modelling. Remote Sensing of Environment, 237, 111524. https://doi.org/10.1016/j.rse.2019.111524

OLSEN, R. C. Remote Sensing from Air and Space. Bellingham, Washington, USA: Spie Press. https://doi.org/10.1117/3.673407

PITTIGLIANI, G. H.; ROLIM, S. B. A. 2017. Biblioteca Espectral do Laboratório de Sensoriamento Remoto Geológico (LabSRGeo): criando uma base de dados para os Sistemas Laguna Barreira do Rio Grande do Sul. In: Anais do XXVIII Salão de Iniciação Científica da UFRGS. Porto Alegre: UFRGS. Available at: <https://lume.ufrgs.br/handle/10183/176790>.

QIN, Z.; KARNIELI, A.; BERLINER, P. 2001. A mono-window algorithm for retrieving land surface temperature from Landsat
TM data and its application to the Israel-Egypt border region. International Journal of Remote Sensing, 22(18), 3719-3746. https://doi.org/10.1080/01431160010006971

ROLIM, S. B. A. et al. 2020. Comparison of emissivity retrieval methods from ASTER data using Fourier-Transform Infrared Spectroscopy. Acta Geophysica, 1-10. Available at: <https: //link.springer.com/article/10.1007/s11600-020-00498-x>.

SAHA, S. et al. 2014. The NCEP climate forecast system version 2. Journal of Climate, 27(6), 2185-2208. Available at: $<$ http://cfs.ncep.>

SEKERTEKIN, A.; BONAFONI, S. 2020. Land Surface Temperature Retrieval from Landsat 5, 7, and 8 over Rural Areas: Assessment of Different Retrieval Algorithms and Emissivity Models and Toolbox Implementation. Remote Sens., 12(2), 294. https://doi.org/10.3390/rs12020294

SOBRINO, J. A. et al. 2008. Land surface emissivity retrieval from different VNIR and TIR sensors. IEEE Trans. Geosci. Remote Sens., $46, \quad 316-327$. https://doi.org/10.1109/TGRS.2007.904834

SOBRINO, J. A. et al. 2004. Land surface temperature retrieval from LANDSAT TM 5, Remote Sens. Environ. 90(4), 434-440. https://doi.org/10.1016/j.rse.2004.02.003

SOBRINO, J. A.; RAISSOUNI, N. 2000. Toward remote sensing methods for landcover dynamic monitoring Int. J. $\begin{array}{lll}\text { Remote } & \text { Sens., } & \text { 353-366. }\end{array}$ https://doi.org/10.1080/014311600210876

TANG, H.; LI, Z.-L. 2014. Quantitative Remote Sensing in Thermal Infrared. Berlin, Heidelberg: Springer Berlin Heidelberg. (Springer Remote Sensing/Photogrammetry). ISBN 978-3-642-42026-9. Available at: <http://link.springer.com/10.1007/978-3-642-42027-6>.

TARDY, B. et al. 2016. A Software Tool for Atmospheric Correction and Surface Temperature Estimation of Landsat Infrared Thermal Data. Remote Sensing, 8(9), 696. https://doi.org/10.3390/rs8090696

USGS. 2020. Earth Explorer. Available at: $<$ https://earthexplorer.usgs.gov/>.

VAN DE GRIEND, A. A.; OWE, M. 1993. On the relationship between thermal emissivity and the normalized difference vegetation index for natural surfaces. Int. J. Remote Sens., 14(6), https://doi.org/10.1080/01431169308904400

$1119-1131$

WALAWENDER, J. P. et al. 2012. A new ArcGIS toolset for automated mapping of land surface temperature with the use of LANDSAT satellite data. IEEE International Geoscience and Remote Sensing Symposium. https://doi.org/10.1109/IGARSS.2012.6350405.

WANG, S. et al. 2015. A temperature and emissivity separation algorithm for Landsat-8 thermal infrared sensor data. Remote Sens., 7, 9904-9927. https://doi.org/10.3390/rs70809904

YU, X. et al. 2014. Land surface temperature retrieval from Landsat 8 TIRS-comparison between radiative transfer equation-based method, split window algorithm and single channel method. Remote Sens., 6, 9829-9852. https://doi.org/10.3390/rs6109829 